\section{Kidney \\ Blood Pressure \\ Research}

Kidney Blood Press Res 2013;37:521-530

\title{
Release From Glomerular Overload by the Addition of Low-dose Thiazide in Patients With Angiotensin Receptor Blocker- Resistant Hypertension
}

\author{
Hajime Hasegawa ${ }^{a, b}$ Yosuke Tayama ${ }^{b}$ Kaori Takayanagi ${ }^{a, b, c} \quad$ Juko Asakura,b \\ Toru Nakamura ${ }^{a}$ Kenji Kawashima ${ }^{a}$ Taisuke Shimizu ${ }^{b}$ Takatsugu Iwashitab \\ Tomonari Ogawab $^{\mathrm{b}}$ Akihiko Matsudab $^{\mathrm{b}}$ Tetsuya Mitaraib \\ aStudy Group of the Saitama Anti-hypertension Losartan-hydrochlorothiazide Trial (SALT), \\ bDepartment of Nephrology and Hypertension, Saitama Medical Center, Saitama Medical University, \\ Kamoda 1981, 'Kawagoe Ekimae Clinic, 16-23 Wakita-Honcho, Kawagoe, Saitama 350-8550 (Japan)
}

\section{Key Words}

Glomerular filtration rate $\cdot$ Renoprotective effect $\bullet$ Losartan $\bullet$ Thiazide $\bullet$ Albuminuria

\begin{abstract}
Background/Aims: This multicenter, prospective, observational study assessed the renoprotective effects of losartan/thiazide combination therapy in terms of lowering the estimated glomerular filtration rate (eGFR). Methods: Adult patients with angiotensin receptor blocker (ARB)-resistant essential hypertension $(n=104)$ were enrolled and switched to combination therapy with losartan ( $50 \mathrm{mg} /$ day) and hydrochlorothiazide ( $12.5 \mathrm{mg} /$ day). Results: eGFR values declined significantly during the first 3 months, and changes in eGFR were assessed according to tertiles of the eGFR decrease ratio at 3 months. Only the high eGFR decrease (1st tertile) group showed significantly greater decreases in baseline eGFR and albumin-to-creatinine ratio (ACR) during the first 3 months. Additionally, the assessment according to tertiles of the baseline eGFR showed a significant decrease in eGFR and ACR during the first 3 months in the high baseline eGFR (1st tertile) group, but not in the moderate (2nd tertile) and low baseline eGFR (3rd tertile) groups. Conclusion: The present results revealed that losartan/thiazide combination therapy attenuated glomerular overload, indicating that this therapy may provide glomerular protection in patients with an elevated GFR without causing prolonged damage to renal function.
\end{abstract}




\section{Kidney Blood Pressure Research}

Kidney Blood Press Res 2013;37:521-530

\begin{tabular}{l|l}
\hline DOI: $10.1159 / 000355732$ & (C) 2013 S. Karger AG, Basel
\end{tabular}

Publisned onlıne: November 16, 2013

www.karger.com/kbr

Hasegawa et al.: Improvement of Glomerular Hyperfiltration by ARB-thiazide Combination

\section{Introduction}

Angiotensin receptor blockers (ARBs) are used commonly for anti-hypertension therapy and have been recommended as a first-line therapeutic strategy in several hypertension guidelines [1-3]. The principal advantage of ARBs are that they exert various protective effects in organs in addition to lowering blood pressure [4-8]. Thiazide diuretic agents are used as second-line drugs for hypertensive patients with ARB resistance and they are also recommended for concomitant use with ARBs in several guidelines [1, 2]. Indeed, a largescale clinical study has reported clinical advantages of an ARB and thiazide combination therapy [9].

We recently conducted a multicenter, prospective, observational study in the Saitama Prefecture of Japan (the Saitama Anti-hypertension Losartan-hydrochlorothiazide Trial: SALT study), wherein we studied the clinical effectiveness of losartan/thiazide combination therapy in patients with hypertension that was resistant to either ARB monotherapy or concomitant ARB + calcium channel blocker (CCB) therapy [10]. The results showed that estimated salt excretion (eSE) at baseline was significantly correlated with the magnitude of blood pressure decrease, and that eSE could predict the efficacy of the combination therapy [10]. The study also demonstrated a significant decrease in the estimated glomerular filtration rate (eGFR) during the first 3 months after the switch to ARB/thiazide combination therapy [10].

It is generally considered that a decrease in the GFR or an increase in serum creatinine $(\mathrm{Cr})$ levels indicates a deterioration in renal function. However, in certain cases, a decreased GFR may indicate attenuation of a pressure overload in the glomerulus. A sub-analysis of the Reduction of Endpoints in NIDDM with the Angiotensin II Antagonist Losartan (RENAAL) study revealed that an acute decrease in the GFR during the initial period after the switch to losartan predicted a slower decrease in long-term renal function, indicating that the initial decrease in GFR provided a long-term renoprotective effect [11]. In addition, a decrease in the GFR at the onset of losartan/thiazide combination therapy generally predicts a subsequent slower decline in renal function, presumably because it reflects a decrease in glomerular pressure [12]. These results strongly suggest that a decline in the GFR does not necessarily indicate a deterioration in renal function. However, the significance of the GFR decrease caused by combined ARB/thiazide therapy has not been studied sufficiently, particularly its relationship with the associated anti-proteinuric effect.

In this study, we performed a sub-analysis of the SALT study to evaluate the clinical significance of the decline in eGFR. This involved assessing the relationships among the decline in eGFR, the baseline values of eGFR, decrease in blood pressure, and changes in albuminuria. The results showed that a significant decline in the eGFR occurred only in patients with high baseline eGFR values. These patients also showed a significant decrease in albuminuria. The results indicated that the renoprotective effect of losartan/thiazide combination therapy was attributable to amelioration of the hyperfiltration state of glomerular hemodynamics. Our findings thus contribute to knowledge about therapeutic strategies for the clinical management of ARB-resistant hypertension and the renoprotection associated with these strategies.

\section{Materials and Methods}

\section{Study subjects}

The SALT study was a multicenter, prospective, observational study. The main outcomes and complete study design, organization, clinical measures, exclusion criteria, and baseline characteristics have been published [10]. The study was conducted in accordance with the principles of the Declaration of Helsinki. The study protocol was approved by the Ethics Committee for Human Studies at Saitama Medical University. We included patients aged 38-85 years with essential hypertension who were administered an ARB with or without the concomitant administration of a CCB over a 1-month period (May 2008 to April 2010). Patients 


\section{Kidney \\ Blood Pressure Research}

Kidney Blood Press Res 2013;37:521-530

\begin{tabular}{l|l}
\hline DOI: 10.1159/000355732 & C 2013 S. Karger AG, Basel
\end{tabular}

Publisnea onine. November 16, 2013

www.karger.com/kbr

Hasegawa et al.: Improvement of Glomerular Hyperfiltration by ARB-thiazide Combination

who did not meet the target blood pressure levels described in the 2004 Japanese Society of Hypertension Guidelines for the Management of Hypertension $(\leq 130 / 85 \mathrm{mmHg}$ for young and middle-aged adults, $\leq 140 / 90 \mathrm{mmHg}$ for adults aged $>75$ years) [13] after this antihypertension therapy and who provided informed consent were enrolled in the SALT study. As described [10], patients were excluded from the study if they had been administered any type of diuretic or thiazolidinedione agent or if they exhibited advanced renal insufficiency (serum $\mathrm{Cr}>2.00 \mathrm{mg} / \mathrm{dL}$ or eGFR $<30 \mathrm{~mL} / \mathrm{min}$ ), heart failure (New York Heart Association functional class III or IV for dyspnea at exertion), or severe liver dysfunction.

Study protocol and clinical profile of the participants

A total of 104 patients who underwent SALT study screening were included in the present study. After blood and urine sampling to obtain baseline laboratory data, the ARB treatment in these patients was switched to the daily administration of a tablet of a compound drug (Preminent ${ }^{\circledR}$ ) that contains losartan (50 $\mathrm{mg}$ ) and hydrochlorothiazide (12.5 mg). The first morning urine was collected for biochemical analysis. The enrolled patients visited individual centers for the measurement of blood pressure and medical interviews until the 12th month. At the 3rd- and 12th-month visits, each patient provided blood and urine samples using methods similar to those used for the baseline sample collection. As described [10], 93 and 74 participants completed the 3-month and 12-month observations, respectively. At the baseline, the patients' mean age was $67.7 \pm 12.6$ years and their mean body mass index (BMI) was $24.6 \pm 3.6 \mathrm{~kg} / \mathrm{m}^{2}$ [10]. The ratio of males was $59.1 \%$ ( 55 cases). The prevalence of obesity was $34.4 \%(n=32)$, diabetes $21.5 \%(n=20)$, and dyslipidemia $44.1 \%(n=41)$. The criteria for diagnosing obesity, diabetes, and dyslipidemia were as follows: obesity, body mass index (BMI) $\geq 25.0 \mathrm{~kg} / \mathrm{m}^{2}$; diabetes, use of antihyperglycemic medication or fasting blood glucose levels $>125 \mathrm{mg} / \mathrm{dL}$; dyslipidemia, use of lipid-lowering medication or total cholesterol levels $\geq 220$ $\mathrm{mg} / \mathrm{dL}$ and/or high-density lipoprotein cholesterol levels $\leq 40 \mathrm{mg} / \mathrm{dL}$ and/ or triglyceride levels $\geq 150 \mathrm{mg} /$ $\mathrm{dL}$. The ARBs being taken by the patients at enrollment and their mean doses were as follows: olmesartan $(n=25,26.9 \%, 20.0 \mathrm{mg} /$ day), losartan ( $n=22,23.7 \%, 50.0 \mathrm{mg} /$ day $)$, valsartan $(n=18,19.4 \%, 92.5 \mathrm{mg} /$ day), telmisartan $(n=14,15.1 \%, 38.7 \mathrm{mg} /$ day $)$, candesartan $(n=11,11.8 \%, 7.6 \mathrm{mg} /$ day $)$, and irbesartan $(n=3,3.2 \%, 100.0 \mathrm{mg} /$ day). Thirty-five patients were receiving concomitant CCB therapy at enrollment in the study, including amlodipine ( $n=20$; mean dose, $5.6 \mathrm{mg}$ /day), long-acting nifedipine $(n=6,23.3 \mathrm{mg} /$ day), azelnidipine ( $n=5,12.8 \mathrm{mg} /$ day), benidipine $(n=2,6.0 \mathrm{mg} /$ day $)$, cilnidipine $(n=1,10.0 \mathrm{mg} /$ day $)$, and nicardipine $(n=1,5.0 \mathrm{mg})$. eSE (g/day) was calculated and assessed as described previously [14]. Briefly, the value was calculated from estimated 24 -h $\mathrm{Na}$ excretion $(24 \mathrm{HUNaV})$ using the following equations proposed by Tanaka et al. [14]:

predicted value of 24 -h urine $\mathrm{Cr}$ (PRCr, mg/day) =

$-2.04 \times$ age $+14.89 \times$ body weight $(\mathrm{kg})+16.14 \times$ height $(\mathrm{cm})-2244.45$

$24 \mathrm{HUNaV}(\mathrm{mEq} /$ day $)=[21.98 \times(\mathrm{uNa} / \mathrm{uCr}) \times \mathrm{PRCr}]^{0.392}$

$\mathrm{eSE}(\mathrm{g} /$ day $)=(58.5 \times 24 \mathrm{HUNaV}) / 1000$

\section{Statistical analysis}

All biochemical parameters except brain natriuretic peptide (BNP) and urine albumin-to-Cr ratio (ACR) are expressed as means \pm standard deviations. BNP and ACR values did not have a parametric distribution; therefore, they are expressed as median and 1st- and 3rd-quartile values. We determined the significance of differences in continuous variables with a parametric distribution by paired $t$-tests if an analysis of variance (ANOVA) demonstrated equal distribution and by Welch's $t$-test if the ANOVA demonstrated a nonequal distribution. The mean values of unpaired variables with a parametric distribution were analyzed using the two-tailed $t$-tests for two groups comparison and two-tailed multiple t-test with a Bonferroni correction for multiple group comparisons followed by ANOVA. The significance of paired and unpaired variables with a nonparametric distribution was evaluated using Wilcoxon's signed-rank test and the Mann-Whitney $U$-test, respectively. All statistical analyses were undertaken using a microcomputer-assisted program with SPSS (ver 20.0) for Windows Xp (SPSS Inc., Chicago, IL, USA). A $p$-value of $<0.05$ was considered significant. 


\section{Kidney \\ Blood Pressure Research}

Table 1. Changes in biochemical parameters

\begin{tabular}{|c|c|c|c|}
\hline & $\begin{array}{c}0 \text { months } \\
(\mathrm{n}=93)\end{array}$ & $\begin{array}{c}3 \text { months } \\
(\mathrm{n}=93)\end{array}$ & $\begin{array}{c}12 \text { months } \\
(\mathrm{n}=74)\end{array}$ \\
\hline \multicolumn{4}{|l|}{ Blood pressure } \\
\hline $\mathrm{SBP}(\mathrm{mmHg})$ & $154.9 \pm 14.9$ & $137.4 \pm 16.9^{* *}$ & $135.2 \pm 14.1^{* *}$ \\
\hline $\mathrm{DBP}(\mathrm{mmHg})$ & $86.9 \pm 12.1$ & $78.6 \pm 11.2^{* *}$ & $76.2 \pm 11.0^{* *}$ \\
\hline \multicolumn{4}{|l|}{ Blood test } \\
\hline Albumin $\left(\mathrm{g} \mathrm{dl}^{-1}\right)$ & $4.33 \pm 0.39$ & $4.28 \pm 0.31$ & $4.25 \pm 0.40$ \\
\hline $\mathrm{Cr}\left(\mathrm{mg} \mathrm{dl}^{-1}\right)$ & $0.71 \pm 0.21$ & $0.80 \pm 0.21^{* *}$ & $0.80 \pm 0.22^{* *}$ \\
\hline eGFR $\quad\left(\mathrm{ml} \mathrm{min}^{-1}\right)$ & $78.8 \pm 19.8$ & $71.8 \pm 19.3^{* *}$ & $71.3 \pm 0.20 .2^{* *}$ \\
\hline Uric acid (mg dl-1) & $5.73 \pm 1.70$ & $5.63 \pm 1.62$ & $5.89 \pm 1.73$ \\
\hline $\mathrm{Na}\left(\mathrm{mEq} \mathrm{l}^{-1}\right)$ & $141.2 \pm 1.6$ & $140.1 \pm 2.1$ & $140.6 \pm 2.4$ \\
\hline $\mathrm{K}\left(\mathrm{mEq} \mathrm{l}^{-1}\right)$ & $4.27 \pm 0.57$ & $4.27 \pm 0.60$ & $4.16 \pm 0.59$ \\
\hline $\mathrm{Cl}\left(\mathrm{mEq} \mathrm{l^{-1 }}\right)$ & $103.7 \pm 2.7$ & $101.9 \pm 3.1$ & $102.0 \pm 2.5$ \\
\hline $\mathrm{TC}\left(\mathrm{mg} \mathrm{dl}^{-1}\right)$ & $202.7 \pm 37.7$ & $200.4 \pm 35.5$ & $187.8 \pm 37.1$ \\
\hline $\mathrm{TG}\left(\mathrm{mg} \mathrm{dl}^{-1}\right)$ & $152.7 \pm 96.4$ & $159.4 \pm 109.5$ & $143.0 \pm 76.7$ \\
\hline $\mathrm{BNP}(\mathrm{pg} \mathrm{ml}-1)$ & $22.9(10.9,37.7)$ & $16.0(6.7,33.6)^{* *}$ & $14.4(5.4,41.0)^{* *}$ \\
\hline FBS (mg dl-1) & $119.4 \pm 51.8$ & $110.7 \pm 33.0$ & $117.6 \pm 39.0$ \\
\hline $\mathrm{A} 1 \mathrm{c}(\%)$ & $5.4 \pm 1.1$ & $5.5 \pm 1.0$ & $5.6 \pm 1.1$ \\
\hline \multicolumn{4}{|l|}{ Urine test } \\
\hline Creatinine ( $\mathrm{g} \mathrm{l}^{-1}$ ) & $0.84 \pm 0.54$ & $0.80 \pm 0.22$ & $0.91 \pm 0.59$ \\
\hline $\mathrm{Na}\left(\mathrm{mEq} \mathrm{gCr}^{-1}\right)$ & $120.8 \pm 51.9$ & $130.8 \pm 66.5$ & $121.1 \pm 57.0$ \\
\hline $\mathrm{K}\left(\mathrm{mEq} \mathrm{l}^{-1}\right)$ & $35.9 \pm 26.9$ & $40.9 \pm 30.4$ & $34.4 \pm 23.4$ \\
\hline $\operatorname{ACR}\left(\mu \mathrm{g} \mathrm{mgCr}^{-1}\right)$ & $11.2(5.8,46.3)$ & $8.7(4.6,16.5)^{* *}$ & $4.6(2.8,14.9)^{* *} \# \#$ \\
\hline \multicolumn{4}{|c|}{$\begin{array}{l}\text { The BNP and ACR results are expressed as median values (in parentheses) because these variables did not } \\
\text { have a parametric distribution. Abbreviations: SBP, systolic blood pressure; DBP, diastolic blood pressure; } \\
\text { eGFR, estimated glomerular filtration rate; BNP, brain natriuretic peptide; FBS, fasting blood sugar; ACR, } \\
\text { albumin-to-creatinine ratio. } \\
{ }^{*} \text { p }<0.05 \text { vs. } 0 \text { months, }{ }^{* *} p<0.01 \text { vs. } 0 \text { months, } \# p<0.05 \text { vs. } 3 \text { months, \#\# p }<0.01 \text { vs. } 3 \text { months }\end{array}$} \\
\hline
\end{tabular}

\section{Results}

Physiological and biochemical parameters

The time-related changes in biochemical parameters as measured in the patients' blood and urine samples are listed in Table 1. Both systolic and diastolic blood pressure decreased significantly within the first 3 months, although no significant change was observed over the next 9 months. The majority of biochemical parameters, including serum potassium levels, uric acid levels, and glucose tolerance, showed no significant change during the 1-year observation period. Significant changes in serum $\mathrm{Cr}$ levels and eGFR were observed in the first 3 months but not in the next 9 months. BNP levels also showed a significant decrease in the first 3 months. Urine analysis showed that ACR decreased significantly in the first 3 months as well as over the following 9 months.

Stratified analysis of baseline parameters by eGFR decrease ratio at 3 months and the time-differential changes in blood pressure, eGFR and ACR in each group

To elucidate the clinical profile of the patients who showed a decrease in eGFR, we first calculated the decrease ratio of eGFR at 3 months to assess the effects of the losartan/ thiazide combination therapy on the changes in eGFR values and the residual albuminuria. The patients were stratified according to tertiles of the eGFR decrease ratio at 3 months. As shown in Table 2, the baseline values of BMI, blood pressure, BNP, ACR, and eSE were not different between the three groups. The baseline eGFR in the high eGFR decrease group (1st tertile) was significantly greater than that in the moderate and low eGFR decrease (2nd and 3rd tertiles) groups. As shown in Fig. 1, the residual albuminuria decreased significantly in the high eGFR decrease group but not in the other two groups. In all three groups, blood pressure showed equal and significant decreases in the first 3 months, with no change over the next 9 months. 


\section{Kidney \\ Blood Pressure Research}

\section{Kidney Blood Press Res 2013;37:521-530}

DOI: $10.1159 / 000355732$

Publisnea onine: November 16, 2013

(C) 2013 S. Karger AG, Basel

www.karger.com/kbr

Hasegawa et al.: Improvement of Glomerular Hyperfiltration by ARB-thiazide Combination

Table 2. Baseline values of parameters in the groups with a high, moderate, and low eGFR decrease ratio

\begin{tabular}{|c|c|c|c|}
\hline parameters & $\begin{array}{l}\text { high eGFR decrease } \\
\text { (1st tertitle) }\end{array}$ & $\begin{array}{c}\text { moderate eGFR decrease } \\
\text { (2nd tertitle) }\end{array}$ & $\begin{array}{l}\text { low eGFR decrease } \\
\text { (3rd tertitle) }\end{array}$ \\
\hline $\mathrm{n}$ & 31 & 31 & 31 \\
\hline eGFR-reduction rate & $0.74 \pm 0.09^{* * \# \#}$ & $0.91 \pm 0.05$ & $1.09 \pm 0.14$ \\
\hline baseline BMI ( $\left.\mathrm{kg} \mathrm{m}^{-2}\right)$ & $24.6 \pm 3.9$ & $24.7 \pm 4.1$ & $24.9 \pm 3.3$ \\
\hline baseline SBP (mmHg) & $157.5 \pm 15.3$ & $154.2 \pm 13.2$ & $149.8 \pm 16.3$ \\
\hline baseline DBP (mmHg) & $87.7 \pm 15.1$ & $85.0 \pm 9.7$ & $88.3 \pm 9.7$ \\
\hline baseline eGFR ( $\left.\mathrm{ml} \mathrm{min}^{-1}\right)$ & $89.6 \pm 31.3^{* \# \#}$ & $71.0 \pm 14.5$ & $74.0 \pm 14.6$ \\
\hline baseline BNP (pg ml-1) & $25.3(17.4,42.4)$ & $27.0(15.8,51.0)$ & $21.5(7.6,35.0)$ \\
\hline baseline ACR $\left(\mu \mathrm{g} \mathrm{mgCr}^{-1}\right)$ & $14.2(5.8,47.3)$ & $10.1(6.1,55.3)$ & $8.6(4.8,17.8)$ \\
\hline baseline eSE (g day ${ }^{-1}$ ) & $10.08 \pm 2.65$ & $10.02 \pm 2.86$ & $9.51 \pm 2.27$ \\
\hline \multicolumn{4}{|c|}{$\begin{array}{l}\text { The first and second tertile values of eGFR decrease were } 0.85 \text { and } 0.99 \text {, respectively. The values of BNP and } \\
\text { ACR represent the median values (in parentheses) because these variables did not have a parametric } \\
\text { distribution. Abbreviations: eGFR, estimated glomerular filtration rate; BNP, brain natriuretic peptide; ACR, } \\
\text { albumin-to-creatinine ratio; eSE, estimated salt excretion. } \\
* * \text { p }<0.01 \text { vs. the moderate eGFR decrease group, \# }<<0.05 \text { vs. the low eGFR decrease group, \#\# } p<0.01 \text { vs. } \\
\text { the low eGFR decrease group }\end{array}$} \\
\hline
\end{tabular}

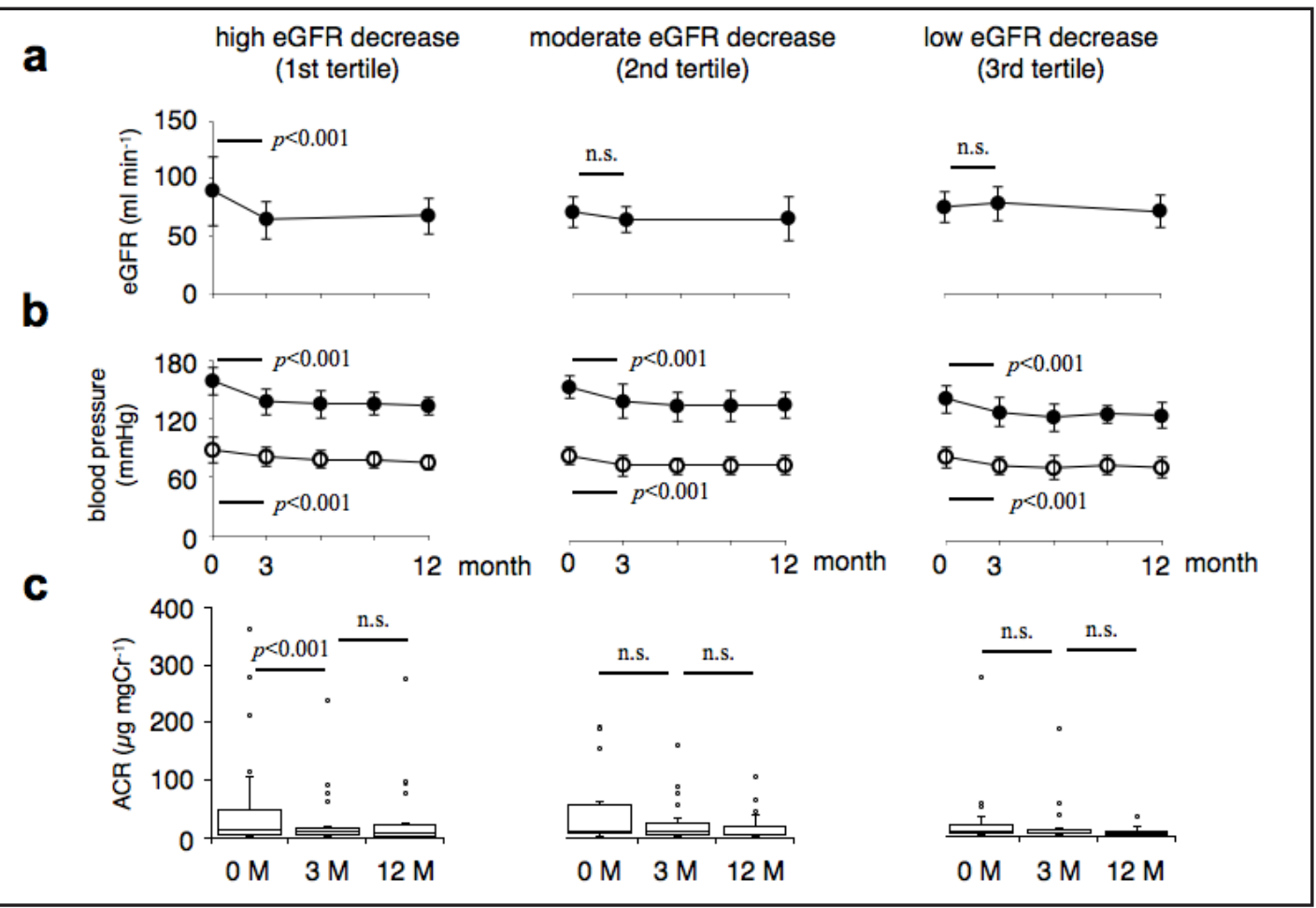

Fig. 1. Tertile analysis of estimated glomerular filtration (eGFR) decrease ratio at the 3 rd month. Time-related changes in eGFR at 0,3 , and 12 months (a) and systolic (closed circles) and diastolic (open circles) blood pressure at 0, 3, 6, 9 and 12 months (b) are expressed as mean \pm SEM in the 1st, 2nd, and 3rd tertiles of eGFR decrease. The urine albumin-to-creatinine ratio at 0,3 , and 12 months (c) are depicted in the box plot, where the box represents the interquartile range (Q1-Q3).

Stratified analysis of baseline parameters by baseline eGFR and the time-differential changes in blood pressure, eGFR and ACR in each group

Because the decreases in eGFR and albuminuria were related to the significant decrease in high baseline eGFR values, we next divided the patients into three tertiles of baseline eGFR values. As shown in Table 3, there was no significant difference in the baseline value of all other parameters, including albuminuria and eSE. The changes in eGFR, blood pressure, and 


\section{Kidney \\ Blood Pressure Research}

Kidney Blood Press Res 2013;37:521-530

DOI: $10.1159 / 000355732$

Published onIIne: November 16, 2013

(C) 2013 S. Karger AG, Basel

www.karger.com/kbr

Hasegawa et al.: Improvement of Glomerular Hyperfiltration by ARB-thiazide Combination

Table 3. Baseline values of parameters in the groups with high, moderate, and low baseline eGFR values

\begin{tabular}{lccc}
\hline parameters & $\begin{array}{c}\text { high baseline eGFR } \\
\text { (1st tertile) }\end{array}$ & $\begin{array}{c}\text { moderate baseline eGFR } \\
\text { (2nd tertile) }\end{array}$ & $\begin{array}{c}\text { low baseline eGFR } \\
\text { (3rd tertile) }\end{array}$ \\
\hline $\mathrm{n}$ & 31 & 31 & 31 \\
baseline eGFR $\left(\mathrm{ml} \mathrm{min}^{-1}\right)$ & $102.2 \pm 25.7^{* * \# \#}$ & $76.1 \pm 5.2$ & $59.3 \pm 8.1$ \\
baseline BMI $\left(\mathrm{kg} \mathrm{m}^{-2}\right.$ ) & $24.6 \pm 3.9$ & $24.1 \pm 3.7$ & $25.1 \pm 3.5$ \\
baseline SBP $\left(\mathrm{mmHg}^{\text {) }}\right.$ & $158.4 \pm 16.0$ & $152.0 \pm 14.7$ & $151.5 \pm 11.8$ \\
baseline DBP $\left(\mathrm{mmHg}^{-1}\right.$ & $90.6 \pm 13.8$ & $84.8 \pm 11.0$ & $85.8 \pm 11.7$ \\
baseline BNP $\left(\mathrm{pg} \mathrm{ml}^{-1}\right)$ & $14.6(7.8,29.6)$ & $22.2(9.6,47.5)$ & $23.8(18.8,36.6)$ \\
baseline ACR $\left(\mu \mathrm{g} \mathrm{mgCr}^{-1}\right)$ & $12.8(5.8,33.6)$ & $10.1(5.9,18.9)$ & $7.7(4.8,40.6)$ \\
baseline eSE $\left(\mathrm{g} \mathrm{day}^{-1}\right)$ & $9.58 \pm 2.85$ & $9.28 \pm 2.34$ & $10.53 \pm 2.79$ \\
age & $63.1 \pm 12.8$ & $68.7 \pm 13.4$ & $70.2 \pm 11.6$ \\
BMI & $24.6 \pm 3.9$ & $24.1 \pm 3.7$ & $25.1 \pm 3.5$ \\
incidence of diabetes & $20.7 \%$ & $16.1 \%$ & $16.7 \%$ \\
\hline
\end{tabular}

The first and second tertile values of baseline eGFR were 85.3 and $68.9 \mathrm{~mL} / \mathrm{min}$, respectively. Values of BNP and ACR represent the median values (in parentheses) because these variables did not have a parametric distribution.

Abbreviations: eGFR, estimated glomerular filtration rate; BNP, brain natriuretic peptide; ACR, albumin-tocreatinine ratio; eSE, estimated salt excretion

${ }^{* *} \mathrm{p}<0.01$ vs. The moderate baseline eGFR group, \#\# $\mathrm{p}<0.01$ vs. the low baseline eGFR group

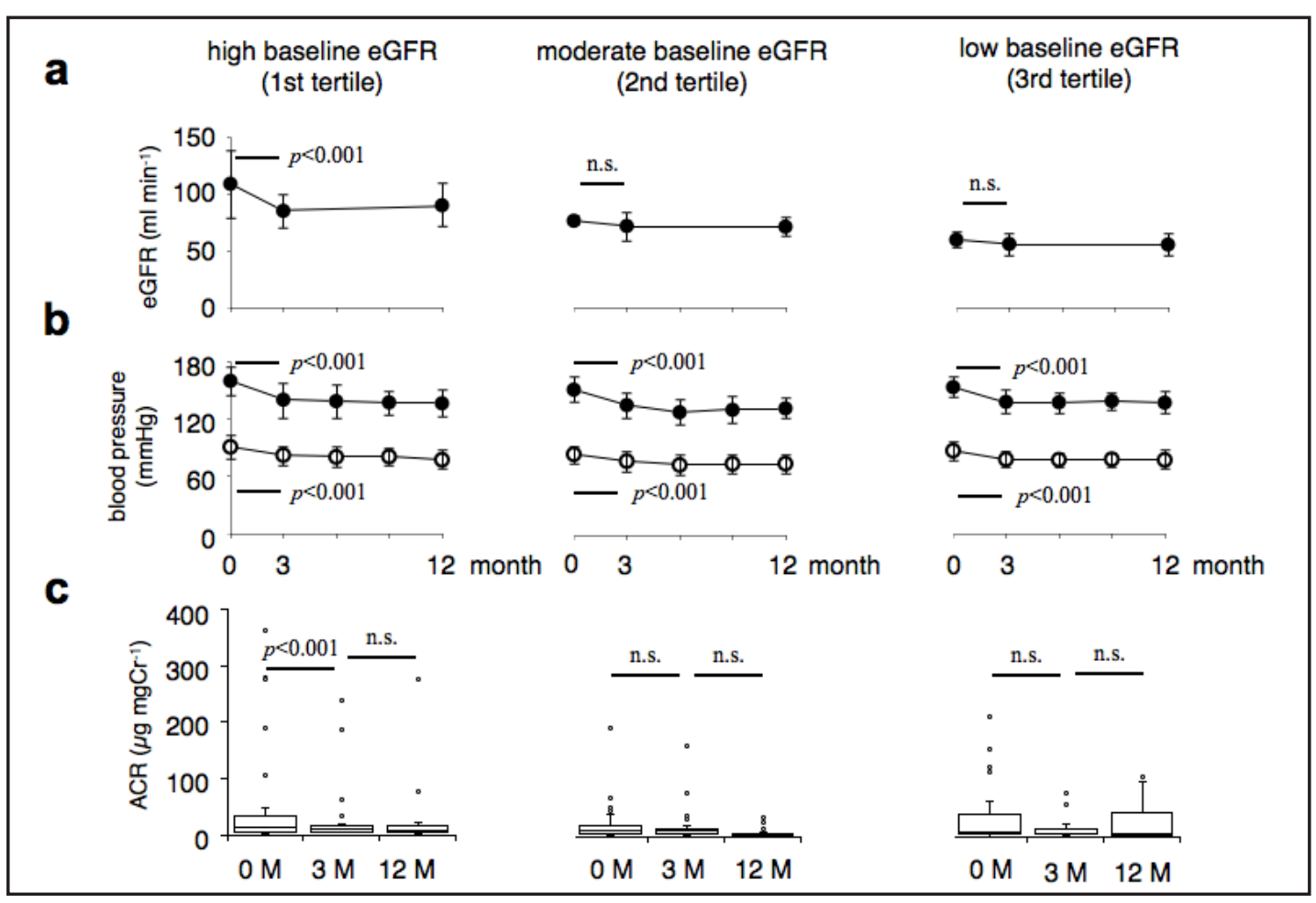

Fig. 2. Tertile analysis of baseline eGFR. Time-related changes in eGFR at 0,3 , and 12 months (a) and systolic (closed circles) and diastolic (open circles) blood pressure at 0, 3, 6, 9, and 12 months (b) are expressed as mean \pm SEM in the 1 st, $2 \mathrm{nd}$, and 3rd tertiles of baseline eGFR. The urine albumin-to-creatinine ratio at 0 , 3 , and 12 months (c) are depicted in the box plot, where the box represents the interquartile range (Q1-Q3).

ACR during the observation period are shown in Fig. 2. Patients in the high baseline eGFR group (1st tertile) exhibited a significant decrease in eGFR during the first 3 months, with no change over the next 9 months. In contrast, patients in the moderate baseline eGFR (2nd tertile and 3rd tertile) groups exhibited no significant change in eGFR during the observation period. Both systolic and diastolic blood pressure decreased equally during the first 3 months in all three groups and remained at this level for the next 9 months, indicating that 


\section{Kidney Blood Pressure Research}

Kidney Blood Press Res 2013;37:521-530

DOI: 10.1159/000355732

Publisned onIIne: November 16, 2013

2013 S. Karger AG, Base

www.karger.com/kbr

Hasegawa et al.: Improvement of Glomerular Hyperfiltration by ARB-thiazide Combination the decrease in eGFR observed in the high baseline eGFR group was independent of the decrease in blood pressure. In contrast, the albuminuria that persisted after ARB monotherapy or ARB + CCB combination therapy decreased during the first 3 months only in the high baseline eGFR group.

As demonstrated in Fig. 3, the univariate analysis of the correlation between the baseline eGFR values and the eGFR decrease at the 3rd month showed an inverse correlation between these variables (correlation coefficient $=0.484, \mathrm{p}<0.01$ ), indicating that patients with a high baseline eGFR achieved a greater decrease in eGFR by the 3rd month.

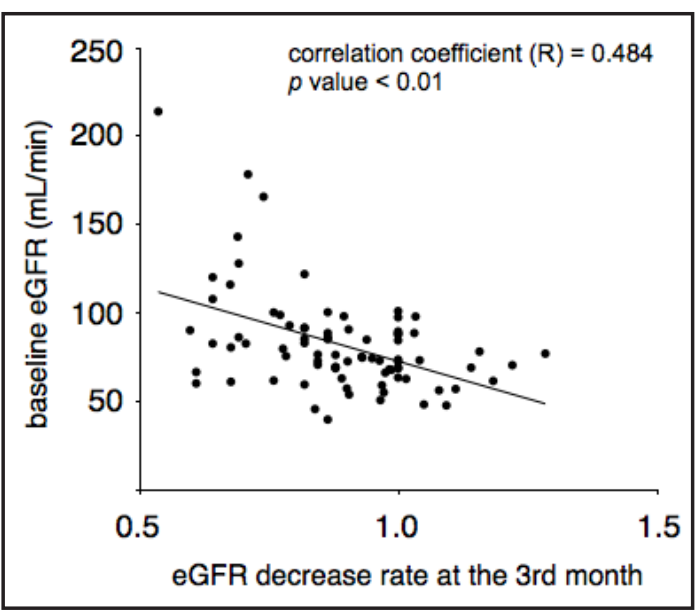

Fig. 3. Correlation between the baseline eGFR and the eGFR decrease ratio at the 3rd month. Individual baseline eGFR values and eGFR decrease ratios at the 3 rd month are plotted by a trend line $(n=93)$.

\section{Discussion}

This study of patients with ARB- or ARB/CCB-resistant hypertension showed that a significant decrease in the eGFR was achieved by switching to losartan/thiazide combination therapy. We observed that the decrease in the eGFR did not occur in all patients, although it occurred independently of changes in systemic blood pressure in the patients with a high baseline eGFR accompanied by a considerable decrease in the eGFR during the first 3 months. This decrease in eGFR was also associated with a significant decrease in albuminuria, which had persisted even after treatment with either ARB monotherapy or ARB/CCB combination therapy.

The finding of a significant decrease in the eGFR during the first 3 months of losartan/ thiazide treatment was in agreement with the results obtained in a previous clinical study [15]. It would be expected that the total body fluid volume would decrease after the addition of thiazide because of the increased elimination of salt. Ito et al. reported that switching to losartan/thiazide combination therapy ameliorated chronic heart failure associated with a decrease in BNP and an increase in Cr levels [16]. These results are compatible with those of the current study. A decrease in body fluid volume and the associated decrease in GFR may be common outcomes after switching to ARB/thiazide treatment.

However, the present study revealed that the decline in ACR was not directly influenced by the decline in body fluid volume and systemic blood pressure. Our stratified analysis of median values of ACR decline during the initial 3 months $(3.1 \mu \mathrm{g} / \mathrm{mgCr})$ showed that the baseline BNP values were not statitically different between the high and low ACR decline groups $(17.5[6.1,35.9] \mathrm{pg} / \mathrm{mL}$ versus $14.9[8.5,28.3] \mathrm{pg} / \mathrm{mL})$ although baseline eGFR values were significantly different between the two groups $(84.8 \pm 29.8$ versus $73.9 \pm 16.4 \mathrm{~mL} / \mathrm{min}$, data not shown in the Result). This observation might indicate that the ACR decline was not directly influenced by the decrease in body fluid volume. The decrease in eGFR values did not occur in all patients in the present study. Our stratified analysis of baseline eGFR values showed a significant decrease only in the patients with the highest baseline values, and the univariate analysis demonstrated an inverse correlation between baseline eGFR values and the eGFR decrease rate at the 3rd month. These results indicate that the switch to losartan/thiazide combination therapy did not cause an equal decrease in eGFR in all patients with ARB-resistant hypertension; this decrease was observed only in the patients with high baseline values or a considerable initial decrease in the eGFR. These patients 


\section{Kidney Blood Pressure Research}

Kidney Blood Press Res 2013;37:521-530

\begin{tabular}{l|l}
\hline DOI: $10.1159 / 000355732$ & (C) 2013 S. Karger AG, Basel
\end{tabular}

Publisnea onine: TNovember 16, 2013

www.karger.com/kbr

Hasegawa et al.: Improvement of Glomerular Hyperfiltration by ARB-thiazide Combination

would be considered to have glomerular hyperfiltration (GHF), a hemodynamic state that results in podocyte damage [17] and is considered to act as a trigger for a further sequential cascade that leads to glomerular sclerosis [18]. The pathological significance of GHF is that a decrease in high baseline eGFR values does not necessarily indicate the development of renal impairment; rather, it indicates correction of the hyperfiltration state in the glomerulus. The blood pressure-independent decrease in albuminuria, which had persisted even after ARB treatment, in association with the significant decrease in eGFR provides evidence that the decrease in eGFR in patients with high baseline eGFR values appears to be a renoprotective effect.

It has been reported that losartan/thiazide combination therapy may further decrease albuminuria that persists after ARB treatment [19]. In addition, concomitant use of telmisartan and thiazide has been shown to result in a significantly greater decrease in albuminuria compared with telmisartan alone [20]. It is generally accepted that the additive effects of combination therapy with an ARB and thiazide on a further decrease in proteinuria are independent of the decrease in blood pressure. Matsui et al. reported that the concomitant use of olmesartan and thiazide resulted in a more obvious antiproteinuric effect compared to the combination of olmesartan and the CCB azelnidipine, whereas the decline in systemic blood pressure was more evident with the latter combination [21]. The findings of the present study are in agreement with these earlier findings in that the significant decrease in albuminuria was not related to the decrease in blood pressure; rather, it was related to the decrease in the eGFR.

A large-scale clinical study targeting patients without diabetes showed that thiazide treatment alone did not have an antiproteinuric effect [22], indicating that the antiproteinuric effect of ARB/thiazide combination therapy was not caused by thiazide alone but was a consequence of the concomitant use of the ARB. Imanishi et al. reported that the severity of albuminuria did not correlate with systemic blood pressure but showed a significant correlation with glomerular pressure, indicating that an elevated GFR may be involved, at least in part, in the development of albuminuria [23]. It is therefore reasonable to suspect that losartan/thiazide combination therapy provides glomerular protection in patients with an elevated GFR, ultimately leading to further glomerular sclerosis. Zhou et al. [24] demonstrated the superior effects of losartan/thiazide combination therapy on whole kidney and glomerular hemodynamics in spontaneous hypertensive rats (SHRs) treated with NG-nitro-L-arginine methyl ester (L-NAME). These rats are used as an experimental model for hypertensive glomerulopathy. The Zhou study revealed a significant and additive decrease in renal vascular resistance (RVR) and glomerular capillary pressure $\left(\mathrm{P}_{\mathrm{G}}\right)$ following a concomitant administration of losartan and a thiazide [24]. These results strongly suggest that the combination therapy affected whole kidney and glomerular hemodynamics to an extent that was sufficient to normalize the pressure load in the glomerulus, leading to improved GHF and a decrease in glomerular injury [24]. The clinical advantage of this combination therapy providing glomerular protection by decreasing the GFR has not been demonstrated clearly, although a series of large-scale clinical trials showed that the blood pressure-lowering effect of combination therapy was potentially greater than that of ARB monotherapy [25-28].

\section{Conclusion}

The present study of patients with ARB-resistant hypertension and elevated GFR showed that combination ARB/thiazide therapy may normalize glomerular hemodynamics, resulting in a protective effect in the glomerulus. The results of the study may contribute to decisionmaking in terms of therapeutic strategies for patients with ARB-resistant hypertension. 


\section{Kidney \\ Blood Pressure Research}

Hasegawa et al.: Improvement of Glomerular Hyperfiltration by ARB-thiazide Combination

\section{Conflict of Interests}

The authors have no conflict of interest to disclose.

\section{Acknowledgments}

This work was supported, in part, by research grants from the Research Foundation for Community Medicine, Utsunomiya, Tochigi, Japan.

\section{References}

1 Ogihara T, Kikuchi K, Matsuoka H, Fujita T, Higaki J, Horiuchi M, Imai Y, Imaizumi T, Ito S, Iwao H, Kario K, Kawano Y, Kim-Mitsuyama S, Kimura G, Matsubara H, Matsuura H, Naruse M, Saito I, Shimada K, Shimamoto K, Suzuki H, Takishita S, Tanahashi N, Tsuchihashi T, Uchiyama M, Ueda S, Ueshima H, Umemura S, Ishimitsu T, Rakugi H: The japanese society of hypertension guidelines for the management of hypertension (JSH 2009). Hypertens Res 2009;32:3-107.

-2 Chobanian AV, Bakris GL, Black HR, Cushman WC, Green LA, Izzo JL, Jr., Jones DW, Materson BJ, Oparil S, Wright JT, Jr., Roccella EJ: The seventh report of the joint national committee on prevention, detection, evaluation, and treatment of high blood pressure: The JNC 7 report. JAMA 2003;289:2560-2572.

$\rightarrow 3$ ESH-ESC: 2003 european society of hypertension-european society of cardiology guidelines for the management of arterial hypertension. J Hypertens 2003;21:1011-1053.

-4 Rossing K, Mischak H, Parving HH, Christensen PK, Walden M, Hillmann M, Kaiser T: Impact of diabetic nephropathy and angiotensin ii receptor blockade on urinary polypeptide patterns. Kidney Int 2005;68:193-205.

5 Roson MI, Della Penna SL, Cao G, Gorzalczany S, Pandolfo M, Toblli JE, Fernandez BE: Different protective actions of losartan and tempol on the renal inflammatory response to acute sodium overload. J Cell Physiol 2010;224:41-48.

-6 de Cavanagh EM, Ferder LF, Ferder MD, Stella IY, Toblli JE, Inserra F: Vascular structure and oxidative stress in salt-loaded spontaneously hypertensive rats: Effects of losartan and atenolol. Am J Hypertens 2010;23:1318-1325.

7 Osorio H, Bautista R, Rios A, Franco M, Santamaria J, Escalante B: Effect of treatment with losartan on salt sensitivity and sglt2 expression in hypertensive diabetic rats. Diabetes Res Clin Pract 2009;86:e46-49.

-8 Satoh M, Haruna Y, Fujimoto S, Sasaki T, Kashihara N: Telmisartan improves endothelial dysfunction and renal autoregulation in dahl salt-sensitive rats. Hypertens Res 2009;33:135-142.

-9 ALLHAT group: Major outcomes in high-risk hypertensive patients randomized to angiotensin-converting enzyme inhibitor or calcium channel blocker vs diuretic: The antihypertensive and lipid-lowering treatment to prevent heart attack trial (allhat). JAMA 2002;288:2981-2997.

10 Hasegawa H, Kanozawa K, Asakura J, Takayanagi K, Komuro S, Fukada H, Tokushima H, Kogure H, Matsuzawa M, Mitarai T: Significance of estimated salt excretion as a predictor of the efficacy of concomitant angiotensin receptor blocker (arb) and low-dose thiazide in patients with arb-resistance. Hypertens Res 2013;36:776-782.

11 Holtkamp FA, de Zeeuw D, Thomas MC, Cooper ME, de Graeff PA, Hillege HJ, Parving HH, Brenner BM, Shahinfar S, Lambers Heerspink HJ: An acute fall in estimated glomerular filtration rate during treatment with losartan predicts a slower decrease in long-term renal function. Kidney Int 2011;80:282-287.

12 Apperloo AJ, de Zeeuw D, de Jong PE: Short-term antiproteinuric response to antihypertensive treatment predicts long-term gfr decline in patients with non-diabetic renal disease. Kidney Int Suppl 1994;45:S174-S178.

13 Japanese Society of Hypertension: Japanese society of hypertension guidelines for the management of hypertension (JSH 2004). Hypertens Res 2006;29:S1-105.

-14 Tanaka T, Okamura T, Miura K, Kadowaki T, Ueshima H, Nakagawa H, Hashimoto T: A simple method to estimate populational 24-h urinary sodium and potassium excretion using a casual urine specimen. J Hum Hypertens 2002;16:97-103. 


\section{Kidney \\ Blood Pressure Research}

Kidney Blood Press Res 2013;37:521-530

\begin{tabular}{l|l}
\hline DOI: $10.1159 / 000355732$ & (c) 2013 S. Karger AG, Basel \\
\hline
\end{tabular}

Publisned online: November 16, 2013

www.karger.com/kbr

Hasegawa et al.: Improvement of Glomerular Hyperfiltration by ARB-thiazide Combination

15 Kita T, Yokota N, Ichiki Y, Ayabe T, Etoh T, Tamaki N, Kato J, Eto T, Kitamura K: One-year effectiveness and safety of open-label losartan/hydrochlorothiazide combination therapy in japanese patients with hypertension uncontrolled with arbs or ace inhibitors. Hypertens Res 2010;33:320-325.

16 Ito H, Ishii K, Kihara H, Kasayuki N, Nakamura F, Shimada K, Fukuda S, Iwakura K, Yoshikawa J: Adding thiazide to a renin-angiotensin blocker improves left ventricular relaxation and improves heart failure in patients with hypertension. Hypertens Res 2012;35:93-99.

$\checkmark 17$ Endlich N, Endlich K: The challenge and response of podocytes to glomerular hypertension. Semin Nephrol 2012;32:327-341.

-18 Hostetter TH: Hyperfiltration and glomerulosclerosis. Semin Nephrol 2003;23:194-199.

19 Vogt L, Waanders F, Boomsma F, de Zeeuw D, Navis G: Effects of dietary sodium and hydrochlorothiazide on the antiproteinuric efficacy of losartan. J Am Soc Nephrol 2008;19:999-1007.

20 Ekinci EI, Thomas G, Thomas D, Johnson C, Macisaac RJ, Houlihan CA, Finch S, Panagiotopoulos S, O'Callaghan C, Jerums G: Effects of salt supplementation on the albuminuric response to telmisartan with or without hydrochlorothiazide therapy in hypertensive patients with type 2 diabetes are modulated by habitual dietary salt intake. Diabetes Care 2009;32:1398-1403.

-21 Matsui Y, Eguchi K, Ishikawa J, Shimada K, Kario K: Urinary albumin excretion during angiotensin ii receptor blockade: Comparison of combination treatment with a diuretic or a calcium-channel blocker. Am J Hypertens 2010;24:466-473.

22 Vogt L, Navis G, Koster J, Manolis AJ, Reid JL, de Zeeuw D: The angiotensin ii receptor antagonist telmisartan reduces urinary albumin excretion in patients with isolated systolic hypertension: Results of a randomized, double-blind, placebo-controlled trial. J Hypertens 2005;23:2055-2061.

-23 Imanishi M, Yoshioka K, Konishi Y, Okumura M, Okada N, Sato T, Tanaka S, Fujii S, Kimura G: Glomerular hypertension as one cause of albuminuria in type ii diabetic patients. Diabetologia 1999;42:999-1005.

-24 Zhou X, Matavelli LC, Ono H, Frohlich ED: Superiority of combination of thiazide with angiotensinconverting enzyme inhibitor or at1-receptor blocker over thiazide alone on renoprotection in l-name/shr. Am J Physiol Renal Physiol 2005;289:F871-879.

25 Bobrie G, Delonca J, Moulin C, Giacomino A, Postel-Vinay N, Asmar R: A home blood pressure monitoring study comparing the antihypertensive efficacy of two angiotensin ii receptor antagonist fixed combinations. Am J Hypertens 2005;18:1482-1488.

-26 Coca A, Calvo C, Sobrino J, Gomez E, Lopez-Paz JE, Sierra C, Bragulat E, de la Sierra A: Once-daily fixedcombination irbesartan $300 \mathrm{mg} /$ hydrochlorothiazide $25 \mathrm{mg}$ and circadian blood pressure profile in patients with essential hypertension. Clin Ther 2003;25:2849-2864.

27 Neutel JM, Saunders E, Bakris GL, Cushman WC, Ferdinand KC, Ofili EO, Sowers JR, Weber MA: The efficacy and safety of low- and high-dose fixed combinations of irbesartan/hydrochlorothiazide in patients with uncontrolled systolic blood pressure on monotherapy: The inclusive trial. J Clin Hypertens (Greenwich) 2005; 7:578-586.

28 Rosenstock J, Rossi L, Lin CS, MacNeil D, Osbakken M: The effects of irbesartan added to hydrochlorothiazide for the treatment of hypertension in patients non-responsive to hydrochlorothiazide alone. J Clin Pharm Ther 1998;23:433-440. 